\title{
KAJIAN METODE COMMISSIONERS, ILLINOIS DAN CANADIAN DALAM MENENTUKAN CADANGAN PADA ASURANSI JIWA DWIGUNA
}

\author{
NUR HASNAH \\ Program Studi Matematika, \\ Fakultas Matematika dan Ilmu Pengetahuan Alam, Universitas Andalas, \\ Kampus UNAND Limau Manis Padang, Indonesia, \\ nurhasnahadityawarman@gmail.com
}

\begin{abstract}
Abstrak. Saat ini industri asuransi berkembang selaras dengan perkembangan dunia usaha pada umumnya. Telah banyak masyarakat di Indonesia yang sudah menyadari betapa pentingnya asuransi, meskipun jika dibandingkan dengan negara lain, Indonesia masih kalah jauh. Kebanyakan masyarakat mengikuti asuransi jiwa karena ingin mengurangi resiko kerugian finansial. Di sisi lain, perusahaan asuransi bisa saja mengalami kerugian ketika terdapat pemegang polis (tertanggung) yang meninggal dunia dan pada saat itu perusahaan tidak mempunyai dana, sedangkan perusahaan tersebut harus mengeluarkan sejumlah dana untuk uang santunan. Oleh karena itu, untuk mengantisipasi kerugian perusahaan, maka sebagian dari premi yang diterima oleh perusahaan harus dicadangkan perusahaan sebagai cadangan premi sehingga bila di masa yang akan datang terjadi klaim maka perusahaan tidak kesulitan membayarnya. Penelitian ini bertujuan untuk menentukan besarnya cadangan yang diperoleh dengan menggunakan metode cadangan yang merupakan perluasan dari cadangan prospektif yaitu cadangan Commissioners, Illinois dan Canadian pada asuransi jiwa Dwiguna. Pada penelitian ini diberikan ilustrasi kasus. Langkah-langkahnya adalah dengan menghitung nilai anuitas awal, premi tahunan bersih, menghitung besarnya premi tahunan yang dimodifikasi, dan menghitung besar cadangan premi di akhir tahun ke-t. Dari hasil analisa perhitungan cadangan premi, walaupun besarnya cadangan premi baik itu cadangan Commissioners,Illinois dan Canadian yang besarnya berbeda beda pada setiap tahunnya tetapi pada akhir periode polis, besarnya cadangan premi adalah sama dan cukup untuk membayarkan uang santunan.
\end{abstract}

Kata Kunci: Cadangan premi, cadangan prospektif, metode Commissioners, metode Illinois dan metode Canadian

\section{Pendahuluan}

Kehadiran industri asuransi merupakan suatu hal yang rasional dan tidak terelakkan oleh sebagian besar pengusaha dan anggota masyarakat untuk menghindari segala bentuk risiko yang mungkin terjadi di masa datang. Kekhawatiran atas segala bentuk risiko seperti risiko kematian, risiko keuangan, risiko kecelakaan dan risiko cacat mendorong pengusaha dan masyarakat untuk mempertanggungkan risiko tersebut pada asuransi. Asuransi sangat bermanfaat bagi pengusaha dan masyarakat untuk mendapatkan jaminan kehidupan jika terjadi hal yang tidak diinginkan. Salah satu asuransi yang dapat diikutsertakan yaitu asuransi jiwa. Pada asuransi jiwa, pihak tertanggung membuat suatu perjanjian dalam ben- 
100 Nur Hasnah

tuk polis dimana tertanggung yang membayar sejumlah uang sebagai premi yang berhubungan atas meninggal dan hidupnya jiwa yang dipertanggungkan. Sebagian dari premi yang diterima oleh perusahaan harus dicadangkan perusahaan sebagai cadangan premi sehingga bila di masa yang akan datang terjadi klaim maka perusahaan tidak kesulitan membayarnya. Perhitungan cadangan premi tanpa memperhitungkan biaya operasional bisa mengakibatkan perusahaan asuransi mengalami kerugian karena besarnya cadangan premi yang diperoleh tidak sesuai dengan perhitungan. Pada paper ini akan dikaji tentang beberapa metode cadangan premi asuransi, yaitu metode cadangan Commissioners, Illinois dan Canadian pada asuransi jiwa Dwiguna. Ketiga metode ini merupakan perluasan dari metode prospektif.

\section{Penentuan Cadangan Pada Asuransi Jiwa Dwiguna}

\subsection{Metode Cadangan Commissioners}

Pada metode cadangan Commissioners terdapat 2 nilai premi bersih yang telah dimodifikasi yaitu:

$\alpha^{(\mathrm{com})}$ : adalah premi bersih untuk tahun pertama,

$\beta^{(\mathrm{com})}$ : adalah premi bersih setiap tahun pada tahun-tahun berikutnya.

Cadangan Commissioners merupakan perluasan dari cadangan full preliminary term. Pada cadangan full preliminary term pada tahun pertama menghasilkan biaya yang tinggi. Jadi, premi tahun pertama hanya cukup untuk menutupi biaya operasional tahun pertama saja atau dengan kata lain cadangan tahun pertama sama dengan nol. Hal ini menyebabkan dikembangkan cadangan Commisioners.

Premi modifikasi cadangan Commissioners dinyatakan dengan persamaan:

$$
\beta^{(\text {com })} \ddot{a}_{x: \overline{n \mid}}=A_{x: \overline{n \mid}}+[(a)-(b)]
$$

dimana $(a)=\left(\beta^{F}\right)$ atau $\left({ }_{19} P_{x+1}\right)$. Diantara kedua rumusan $a$ tersebut, dipilih $a$ dengan nilai perhitungan yang paling kecil, dengan $b=\frac{C_{x}}{D_{x}}$. Selanjutnya, $\beta^{F}$ dirumuskan dengan

$$
\beta^{F}={ }_{m-1} P_{x+1: \overline{n-1 \mid}}
$$

dari persamaan (2.1), maka

$$
\left(\text { ??) } \beta^{c o m}=P_{x: \overline{n \mid}}+\frac{[(a)-(b)]}{\ddot{a}_{x: \bar{n} \mid}}\right.
$$

Nilai sekarang dari keseluruhan premi bersih pada permulaan kontrak asuransi dinyatakan dengan

$$
{ }_{m} P_{x: \bar{n} \mid} \ddot{a}_{x: \bar{m} \mid}=\alpha^{(\mathrm{com})}+\beta^{(\mathrm{com})}\left(\ddot{a}_{x: \bar{m} \mid}-1\right)
$$

Dari persamaan (2.3), diperoleh

$$
\alpha^{c o m}=\beta^{c o m}-[(a)-(b)]
$$


Untuk asuransi jiwa dwiguna dengan lama masa pertanggungan $n$ tahun dan tertanggung berusia $x$, dengan jangka waktu pembayaran premi selama $m$ tahun yang dibayarkan di awal tahun, maka persamaan (??) menjadi.

$$
\beta^{(\mathrm{com})}={ }_{m} P_{x: \overline{n \mid}}+\frac{(a)-(b)}{\ddot{a}_{x: \bar{m} \mid}}
$$

Selanjutnya $\beta^{(\mathrm{com})}$ digunakan untuk perhitungan cadangan dengan menggunakan metode prospektif. Sehingga untuk besarnya cadangan dari tahun ke-t sampai ke $n$ adalah

$$
\begin{aligned}
& { }_{t}^{m} V_{x: \bar{n} \mid}^{(\mathrm{com})}=A_{x+t: \overline{n-t \mid}}-\beta^{(\mathrm{com})} \ddot{a}_{x+t: \overline{m-t \mid}} ; t<m \\
& { }_{t}^{m} V_{x: \bar{m} \mid}^{(\mathrm{com})}=A_{x+t: \overline{n-t \mid}} ; t \geqslant m
\end{aligned}
$$

\subsection{Metode Cadangan Illinois}

Metode cadangan Illinois adalah metode perhitungan cadangan dengan batasan 20 tahun pembayaran. Premi yang dimodifikasi pada metode cadangan Illinois merupakan premi tahunan yang telah dipengaruhi biaya operasional, sehingga terdapat tiga nilai premi bersih yang telah dimofikasi pada metode Illinois yaitu:

$\alpha^{I}$ : adalah premi bersih pada tahun pertama,

$\beta^{I}$ : adalah premi bersih untuk setiap tahun selama 19 tahun berikutnya,

$P$ : adalah premi bersih untuk tahun-tahun selanjutnya.

Premi bersih modifikasi pada metode Illinois dinyatakan dengan persamaan

$$
\beta^{(I)}-\alpha^{(I)}=\left({ }_{19} P_{x+1}-\frac{C_{x}}{D_{x}}\right)
$$

dengan $\frac{C_{x}}{D_{x}}$ adalah premi berjangka 1 tahun yang diperpanjang setiap tahunnya sampai jangka waktu tertentu.

$$
\alpha^{(I)}=\beta^{(I)}-\left({ }_{19} P_{x+1}-\frac{C_{x}}{D_{x}}\right)
$$

Untuk polis dengan pembayaran premi $\leqslant 20$ tahun, maka persamaan umum metode cadangan Illinois dapat dituliskan sebagai berikut

$$
\alpha^{(I)}+\beta^{(I)} a_{x: \overline{k-1 \mid}}={ }_{m} P_{x: \bar{n} \mid} \ddot{a}_{x: \bar{k} \mid}
$$

dengan $k$ adalah nilai terkecil dari $n$ dan 20. Nilai $n$ menyatakan jangka waktu pembayaran premi. Subsitusikan persamaan (2.8) ke persamaan (2.9) kita dapatkan:

$$
\beta^{(I)}={ }_{m} P_{x: \bar{n} \mid}+\frac{{ }_{19} P_{x+1}-\frac{C_{x}}{D_{x}}}{\ddot{a}_{x: \bar{k} \mid}}
$$

Selanjutnya $\beta^{(I)}$ akan digunakan untuk perhitungan cadangan dengan menggunakan metode prospektif. Sehingga untuk besarnya cadangan dari tahun ke $-t$ 
sampai ke $n$ adalah

$$
\begin{aligned}
& { }_{t}^{m} V_{x}: \overline{n \mid}^{(I)}=A_{x+t: \overline{n-t \mid}}-\beta^{I} . \ddot{a}_{x+t: \overline{20-t \mid}}-{ }_{m} P_{x: \overline{\mid} \mid}[20-t \mid m-20 \\
& \left.\ddot{a}_{x+t}\right] ; t \leqslant 20(2.11) \\
& { }_{t}^{m} V_{x}: \overline{n \mid}^{(I)}=A_{x+t: \overline{n-t \mid}}-{ }_{m} P_{x: \overline{n \mid}} \ddot{a}_{x+t: \overline{m-t \mid}} ; 20<t \leqslant m \\
& { }_{t}^{m} V_{x}: \overline{n \mid}^{(I)}=A_{x+t: \overline{n-t \mid}} ; m<t<n
\end{aligned}
$$

\subsection{Metode Cadangan Canadian}

Metode cadangan Canadian adalah metode perhitungan cadangan dengan menyetarakan antara premi modifikasi awal metode Canadian dan premi bersih dengan selisih antara premi bersih untuk polis asuransi jiwa seumur hidup dengan premi natural, maka premi awal modifikasi dengan metode cadangan Canadian dinyatakan dengan

$$
\alpha^{(\mathrm{can})}={ }_{m} P_{x: \bar{n} \mid}-\left(P_{x}-\frac{C_{x}}{D_{x}}\right)
$$

dimana $\frac{C_{x}}{D_{x}}$ adalah premi natural yaitu premi berjangka 1 tahun yang diperpanjang setiap tahunnya sampai jangka waktu tertentu.

Nilai sekarang dari keseluruhan premi bersih pada permulaan kontrak asuransi dinyatakan dengan

$$
{ }_{m} P_{x: \overline{n \mid}} \cdot \ddot{a}_{x: \overline{m \mid}}=\alpha^{(\text {can })}+\beta^{(\text {can })}\left(\ddot{a}_{x: \bar{m} \mid}-1\right)
$$

Subsitusikan persamaan (2.14) ke persamaan (2.15) diperoleh premi modifikasi perpanjangan metode Canadian yaitu:

$$
\beta^{(\text {can })}={ }_{m} P_{x: \bar{n} \mid}+\frac{P_{x}-\frac{C_{x}}{D_{x}}}{\ddot{a}_{x: \bar{m}}-1}
$$

Selanjutnya $\beta^{(\text {can })}$ akan digunakan untuk perhitungan cadangan dengan menggunakan metode prospektif, sehingga diperoleh

$$
\begin{aligned}
& { }_{t}^{m} V_{x: \overline{n \mid}}^{(\text {can })}=A_{x+t: \overline{n-t \mid}}-\beta^{(\text {can })} . \ddot{a}_{x+t: \overline{m-t \mid}} ; t<m \\
& { }_{t}^{m} V_{x: \overline{n \mid}}^{(\text {can })}=A_{x+t: \overline{n-t \mid}} ; t \geqslant m
\end{aligned}
$$

\subsection{Ilustrasi Kasus}

Pak Romi yang berusia 40 tahun hendak mengikuti polis asuransi jiwa di suatu perusahaan asuransi dan memilih salah satu produk asuransi jiwa yaitu asuransi jiwa dwiguna dengan lama masa pertanggungan 25 tahun, jangka waktu pembayaran premi 21 tahun, uang santunan sebesar 200 juta dan jika tertanggung hidup setelah masa pertanggungan, maka tertanggung akan mendapatkan manfaat hidup(tabungan) sebesar 20 juta. Dari ilustrasi tersebut diketahui :

- Usia Pak Romi 40 tahun yang dimisalkan dengan $x=40$.

- Santunan sebesar 200 juta, yang dimisalkan dengan $R=200$ juta,

- Lama masa pertanggungan 25 tahun yang dimisalkan dengan $n=25$, 
- Jangka waktu pembayaran premi 21 tahun yang dimisalkan dengan $m=21$,

- Tingkat suku bunga 0,025 yang dimisalkan dengan $i=0,025$.

Pada contoh kasus ini, perusahaan asuransi akan menghitung besarnya cadangan premi dengan tiga metode, yaitu metode cadangan Commissioners, metode cadangan Illinois dan metode cadangan Canadian.

Tabel yang digunakan dalam perhitungan premi adalah Tabel Mortalitas Indonesia tahun 1999 dengan tingkat suku bunga $i=2,5 \%$.

Setelah dilakukan perhitungan, diperoleh nilai-nilai

a) Premi tahunan bersih yang akan dibayarkan selama 21 tahun adalah Rp. 7.070.207, 2629,-

b) Besarnya nilai sekarang santunan pada tahun pertama adalah Rp. 115.376.705, 8392, -

c) Perhitungan anuitas selama masa pertanggungan yang dibayarkan setiap awal periode:

- Lama masa pertanggungan 25 tahun dan pembayaran premi tiap awal tahun untuk kasus pak Romi yang berusia 40 tahun, yaitu

$$
\ddot{a}_{x: \bar{n} \mid}=17,886236 .
$$

- Lama masa pertanggungan 25 tahun, jangka waktu pembayaran 21 tahun dan pembayaran premi dilakukan tiap awal tahun, yaitu

$$
\ddot{a}_{x: \bar{m} \mid}=15,9472 .
$$

- Lama masa pertanggungan 25 tahun, jangka waktu pembayaran premi 21 tahun, pembayaran premi dilakukan tiap awal tahun, maka nilai sekarang untuk pembayaran anuitas diwaktu yang akan datang pada cadangan tahun ke $-t$ yaitu

$$
\ddot{a}_{x+t: \overline{m-t \mid}} .
$$

Besarnya nilai sekarang untuk pembayaran anuitas diwaktu yang akan datang pada tahun pertama adalah 15,3557 ,

- Nilai sekarang untuk pembayaran anuitas diwaktu yang akan datang pada metode cadangan Illinois dengan batasan pembayaran premi 20 tahun yaitu

$$
\ddot{a}_{x+t: \overline{20-t \mid}} \text {. }
$$

Perhitungan anuitas pada tahun pertama adalah 14.8040

d) Besarnya cadangan premi dengan menggunakan metode Commissioners di akhir tahun pertama adalah Rp. 1.385.770,3276,-

e) Besarnya cadangan premi dengan menggunakan metode Illinois di akhir tahun pertama adalah Rp. 1.398.414,0753, - .

f) Besarnya cadangan premi dengan menggunakan metode Canadian di akhir tahun pertama adalah Rp.-83.117.567,6244,--

Berikut akan dibandingkan besarnya nilai cadangan dengan menggunakan metode cadangan Commissioners, metode cadangan Illinois dan metode cadangan Canadian pada Tabel 1. 
Tabel 1 Perbandingan besarnya nilai cadangan dengan menggunakan metode Commissioners, Illinois dan Canadian untuk kasus pak Romi yang berusia 40 tahun pada asuransi jiwa dwiguna dengan lama masa pertanggungan 25 tahun dan jangka waktu pembayaran premi 21 tahun.

\begin{tabular}{|c|c|c|c|}
\hline$t$ & $m_{t}^{m} V_{x=\bar{n} \mid}^{(c o m)}$ & ${ }_{i}^{m} V_{x \cdot \bar{n} \mid}^{(t)}$ & ${ }_{t}^{m_{t}} V_{x \bar{n} \mid}^{(\operatorname{can})}$ \\
\hline 1 & $1.385 .770,3276$ & $1.398 .414,0753$ & $-83.117 .567,6244$ \\
\hline 2 & $8.565 .522,8328$ & $8.591 .159,8325$ & $-72.606 .446,6975$ \\
\hline 3 & $15.912 .327,4866$ & $15.951 .321,3369$ & $-61.849 .501,6238$ \\
\hline 4 & $23.425 .536,2221$ & $23.478 .267,3451$ & $-50.847 .311,2833$ \\
\hline 5 & $31.103 .677,3352$ & $31.170 .546,2399$ & $-39.601 .562,3625$ \\
\hline 6 & $38.946 .503,8869$ & $39.027 .934,4532$ & $-28.112 .126,2262$ \\
\hline 7 & $46.948 .518,8787$ & $47.044 .966,1065$ & $-16.386 .206,1710$ \\
\hline 8 & $55.109 .514,0555$ & $55.221 .467,8368$ & $-4.423 .381,6931$ \\
\hline 9 & $63.434 .169,4994$ & $63.562 .157,5939$ & $7.783 .803,7074$ \\
\hline 10 & $71.930 .240,7605$ & $72.074 .832,4456$ & $20.247 .269,2505$ \\
\hline 11 & $80.609 .723,4585$ & $80.771 .531,2151$ & $32.985 .018,6462$ \\
\hline 12 & $89.491 .903,5013$ & $89.671 .577,6259$ & $46.025 .414,4922$ \\
\hline 13 & $98.597 .083,7399$ & $98.795 .313,7219$ & $59.398 .025,9126$ \\
\hline 14 & $107.949 .174,8987$ & $108.166 .681,1124$ & $73.137 .807,7410$ \\
\hline 15 & $117.563 .822,6705$ & $117.801 .378,6119$ & $87.268 .107,1153$ \\
\hline 16 & $127.453 .398,7036$ & $127.711 .854,3649$ & $101.808 .149,1883$ \\
\hline 17 & $137.629 .068,3821$ & $137.909 .385,1245$ & $116.776 .154,9138$ \\
\hline 18 & $148.107 .897,6925$ & $148.411 .173,4728$ & $132.199 .283,0081$ \\
\hline 19 & $158.914 .747,6058$ & $159.242 .243,9202$ & $148.116 .367,9972$ \\
\hline 20 & $170.087 .112,2654$ & $170.440 .244,4720$ & $164.584 .069,7275$ \\
\hline 21 & $181.672 .203,3566$ & $181.672 .203,3566$ & $181.672 .203,3566$ \\
\hline 22 & $185.981 .998,4084$ & $185.981 .998,4084$ & $185.981 .998,4084$ \\
\hline 23 & $190.458 .021,8281$ & $190.458 .021,8281$ & $190.458 .021,8281$ \\
\hline 24 & $195.121 .951,8274$ & $195.12 .1951,8274$ & $195.121 .951,8274$ \\
\hline 25 & $200.000 .000,0000$ & $200.000 .000,0000$ & $200.000 .000,0000$ \\
\hline
\end{tabular}




\section{Kesimpulan}

Pada paper ini, dibahas tentang perhitungan cadangan premi dengan menggunakan metode yang merupakan perluasan dari metode prospektif, yaitu metode cadangan Commissioners, Illinois dan Canadian dengan hasil perhitungan sebagai berikut

(1) Perhitungan nilai cadangan premi dengan menggunakan metode cadangan Commissioners.

Untuk asuransi jiwa dwiguna (endowment) $n$ tahun dan usia tertanggung $x$ tahun dengan santunan yang dibayar di akhir periode dan jangka waktu pembayaran premi $m$ tahun, nilai cadangan Commissioners pada waktu ke $t$ dinotasikan sebagai :

$$
\begin{aligned}
& { }_{t}^{m} V_{x: \bar{n} \mid}^{(\mathrm{com})}=A_{x+t: \overline{n-t \mid}}-\beta^{(\mathrm{com})} \ddot{a}_{x+t: \overline{m-t \mid}}, t<m \\
& { }_{t}^{m} V_{x: m \mid}^{\left(\frac{c o m}{m}\right)}=A_{x+t: \overline{n-t \mid}}, t \geqslant m
\end{aligned}
$$

(2) Perhitungan nilai cadangan premi dengan menggunakan metode cadangan Illinois.

Untuk asuransi jiwa dwiguna (endowment) $n$ tahun dan usia tertanggung $x$ tahun dengan santunan yang dibayar di akhir periode dan jangka waktu pembayaran premi $m$ tahun, nilai cadangan Illinois pada waktu ke $t$ dinotasikan sebagai :

$$
\begin{aligned}
& { }_{t}^{m} V_{x: \overline{n \mid}}^{(I)}=A_{x+t: \overline{n-t \mid}}-\beta^{I} . \ddot{a}_{x+t: \overline{20-t \mid}}-{ }_{m} P_{x: \overline{n \mid}}[20-t \mid m-20 \\
& { }_{t}^{m} V_{x: \bar{a} \mid}^{(I)}=A_{x+t: \overline{n-t \mid}}-{ }_{m} P_{x: \overline{n \mid}} \ddot{a}_{x+t: \overline{m-t \mid}} ; 20<t \leqslant m \\
& { }_{t}^{m} V_{x: \overline{n \mid}}^{(I)}=A_{x+t: \overline{n-t \mid}} ; m<t<n
\end{aligned}
$$

(3) Perhitungan nilai cadangan premi dengan menggunakan metode cadangan Canadian.

Untuk asuransi jiwa dwiguna (endowment) $n$ tahun dan usia tertanggung $x$ tahun dengan santunan yang dibayar di akhir periode dan jangka waktu pembayaran premi $m$ tahun, nilai cadangan Canadian pada waktu ke $t$ dinotasikan sebagai :

$$
\begin{aligned}
& { }_{t}^{m} V_{x: \bar{n} \mid}^{(\text {can })}=A_{x+t: \overline{n-t \mid}}-\beta^{(\text {can })} \cdot \ddot{a}_{x+t: \overline{m-t} \mid} ; t<m \\
& { }_{t}^{m} V_{x: \bar{n} \mid}^{(\text {can })}=A_{x+t: \overline{n-t \mid}} ; t \geqslant m
\end{aligned}
$$

Dari hasil analisa perhitungan cadangan premi, meskipun di awal besarnya cadangan prospektif, Commissioners, Illinois dan Canadian berbeda-beda, tetapi pada akhir periode polis, besarnya cadangan premi adalah sama dan cukup untuk membayarkan uang santunan.

\section{Ucapan Terima kasih}

Penulis mengucapkan terima kasih kepada Bapak Dr. Dodi Devianto, Dr. Admi Nazra, Ibu Riri Lestari, M.Si, Ibu Hazmira Yozza, M.Si dan Bapak Dr. Jenizon 
106 Nur Hasnah

yang telah memberikan masukan dan saran sehingga jurnal ini dapat diselesaikan dengan baik.

\section{Daftar Pustaka}

[1] Futami, Takashi. 1993.Matematika Asuransi Jiwa Bagian I. Tokyo: Incorporated Foundation Oriental Life Insurance Cultural Development Center.

[2] Futami, Takashi. 1994.Matematika Asuransi Jiwa Bagian II. Tokyo: Incorporated Foundation Oriental Life Insurance Cultural Development Center.

[3] Larson R.E. dan E.A. Gaumnitz. 1951. Life Insurance Mathematics. New York: John Wiley and Sons, Inc

[4] Salim, A. 2007. Asuransi dan Manajemen Risiko. Jakarta: Raja Grafindo Persada.

[5] Sembiring, R.K. 1986. Buku Materi Pokok Asuransi I. Jakarta: Karunika, Universitas Terbuka.

[6] Sitanggang, C., D. Kerami. 2003. Kamus Matematika. Jakarta: Balai Pustaka. 